\title{
Radiotherapeutic Options for Symptom Control in Breast Cancer
}

\author{
Birgitt van Oorschot ${ }^{a} \quad$ Gabriele Beckmann $^{\mathrm{a}} \quad$ Wolfgang Schulze $^{\mathrm{b}} \quad$ Dirk Rades $^{\mathrm{c}} \quad$ Petra Feyer $^{\mathrm{d}}$ \\ aDepartment of Radiation Oncology, University of Würzburg, \\ ${ }^{b}$ Palliative Ward, Clinical Center Bayreuth, \\ 'Department of Radiation Oncology, University Hospital Schleswig-Holstein, Campus Lübeck, \\ ${ }^{\mathrm{d}}$ Radiation Oncology, Clinic for Radiotherapy, Nuclear Medicine Vivantes - Clinical Center Neukölln, Berlin, Germany
}

\section{Keywords}

Radiotherapy - Breast cancer - Symptom control .

Palliative care

\section{Summary}

The majority of breast cancer patients will require radiation therapy at some time during the course of their disease. An estimated $30-50 \%$ of all radiation treatments are of palliative nature, either to alleviate symptoms or prophylactic to prevent deterioration of quality of life due to locally progressive disease. Radiotherapy is a locally effective tool, and typically causes no systemic and mostly mild acute side effects. The following article provides an overview of options and decision-making in palliative radiotherapy for symptom control.

\section{Introduction}

Many breast cancer patients receive one or several radiotherapy treatments throughout the course of their disease. Adjuvant radiotherapy reduces the risk of local recurrence and increases overall survival. Palliative radiotherapy is indicated to treat metastases that produce local symptoms or are expected to do so during the lifespan of the patient. Symptom relief is not only achieved by reduction of tumor size. Radiotherapy also has an anti-inflammatory, anti-secretory, antiedematous, and analgesic effect, even at low doses. Local radiotherapy is efficient, safe, has few side effects, and is costeffective. Metastatic breast cancer is a heterogeneous disease;

\author{
Schlüsselwörter \\ Strahlentherapie - Mammakarzinom . \\ Symptomlinderung $\cdot$ Palliativmedizin
}

\section{Zusammenfassung}

Die Mehrzahl der Patientinnen mit Brustkrebs erhält im Krankheitsverlauf einmalig oder mehrfach eine lokale Strahlentherapie, 30-50\% der Behandlungen erfolgen unter palliativer Zielsetzung, entweder zur Linderung belastender Symptome oder palliativ-präventiv zur Sicherung der Lebensqualität durch die Vermeidung lokaler Komplikationen oder eines lokalen, zeitbegrenzten Tumorprogresses. Strahlentherapie ist ein lokal wirksames Verfahren mit zumeist nur leichten Nebenwirkungen. Der vorliegende Artikel gibt einen Überblick über die Möglichkeiten der palliativen Strahlentherapie zur Symptomlinderung und über die medizinische Entscheidungsfindung.

the clinical course depends on several factors such as pattern of metastasis, tumor burden, interval between primary diagnosis and occurrence of metastasis as well as on biological tumor parameters such as receptor status and grading. Metastatic disease may be indolent with long-lasting remissions, or aggressive with rapid progression and death.

\section{Intention and Goals}

It is important to consider the following in order to define the goal of treatment: i) Palliative symptom-oriented radiotherapy is initiated to alleviate patients' symptoms such as

\section{KARGER \\ Fax +497614520714 \\ Information@Karger.de}

www.karger.com (c) 2011 S. Karger GmbH, Freiburg

$1661-3791 / 11 / 0061-0014 \$ 38.00 / 0$

Accessible online at:

www.karger.com/brc
Dr. med. Birgitt van Oorschot

Interdisciplinary Center Palliative Medicine

Department of Radiation Oncology, University of Würzburg

Josef-Schneider-Str. 11, 97080 Würzburg, Germany

Tel. +49 931 201-28857, Fax -28873

oorschot_b@klinik.uni-wuerzburg.de 


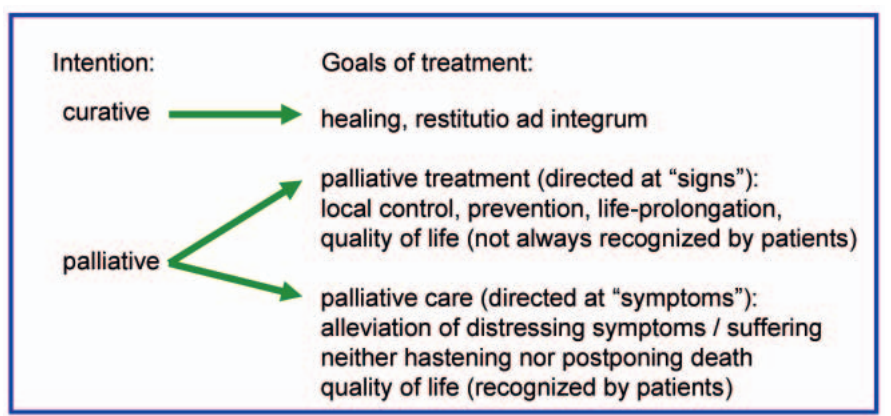

Fig. 1. Intentions and goals.

pain, distress, dysphagia, paresis, or unpleasant smells. Side effects are avoided, and stress levels during treatment are kept as low as possible. The underlying disease is barely influenced, and prolongation of life is not intended but may be an additional effect because of better symptom management. ii) Palliative sign-oriented radiotherapy aims at avoiding future symptoms or complications, achieving (temporary) local control, and perhaps also prolonging patients' lives. Side effects are accepted to a certain extent and are to be balanced against the benefit for the patient. The main objective is always an individualized approach and to retain or improve quality of life (fig. 1). Several guidelines recommend the use of radiotherapy for symptom control in metastatic breast cancer. For Germany, these are the S3 guideline of the AWMF (Arbeitsgemeinschaft der Wissenschaftlichen Medizinischen Fachgesellschaften), and the guidelines of the AGO (Arbeitsgemeinschaft Gynäkologische Onkologie) and the DEGRO (Deutsche Gesellschaft für Radioonkologie) [1-4]. Randomized trials and retrospective data reporting on the effect of palliative radiotherapy often do not discriminate between metastases of different tumor entities. This is reasonable because achievement of symptom control and local control is the primary aim of treatment and the endpoint of analysis, even if special characteristics of metastatic breast cancer may not be addressed in this setting.

\section{Bone Metastases: Pain and Neurological Symptoms}

About $20 \%$ of patients with breast cancer suffer from bone metastases [5]. Less than $10 \%$ of patients with bone metastases will develop metastatic spinal cord compression (MSCC) with neurological symptoms, usually late in the course of disease [6]. The signs and symptoms of a skeletal metastasis largely depend on the location and the mechanical stress on the affected bone parts. The American College of Radiology Appropriateness Criteria Expert Panel on Radiation Oncology published guidelines for radiotherapy of bone metastases [7]. Randomized trials comparing multifraction short-term versus long-term radiotherapy represent about 20-43\% women with breast cancer $[8,9]$.

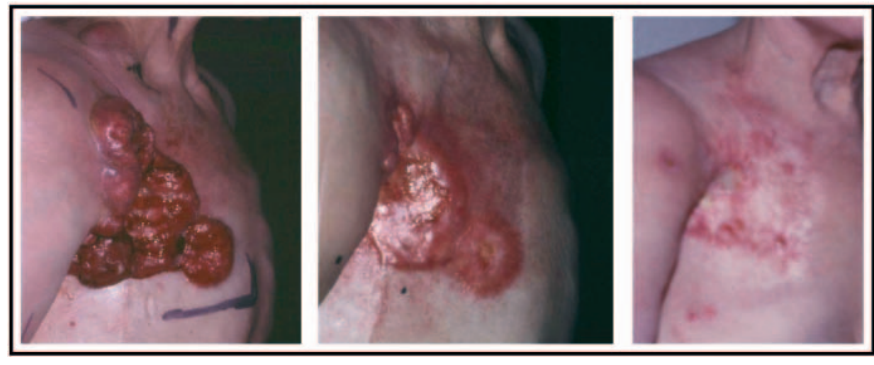

Fig. 2. Clinical Case: pain, lymphedema, bleeding and exulceration before, two months and 3 years after radiotherapy.

\section{Alleviation of Pain Caused by Bone Metastases}

Rades [8] presented an overview of dose fractionation schedules for radiotherapy of bone metastases in breast cancer patients. Irradiation of bone metastases for symptom control to relieve pain can be performed with $1 \times 8 \mathrm{~Gy}$. Meta-analyses have shown that one-time irradiation of uncomplicated bone metastases (no fracture, no neurological deficits) relating to analgesia without intensifying toxicity is as effective as fractionated irradiation. In up to $66-87 \%$ of patients, significant pain relief can be achieved, in $31-61 \%$ complete pain remission (overview in [8] table 3). Radiotherapy is also effective in neuropathic bone pain $(25 \%$ complete and $32 \%$ partial response, no difference $1 \times 8$ Gy vs. $10 \times 3$ Gy [10]). Pain relief results in both an improved quality of life and a significant reduction of pain medication required (fig. 2) [11, 12]). The analgesic effect of radiotherapy usually sets in within 1-3 weeks after the start of irradiation. In some patients, increased temporary pain is observed (flare phenomenon), which can be effectively treated with dexamethasone. Therefore, pain medication should be initiated according to the World Health Organization scheme. Medication has to be adjusted individually in the course of treatment to prevent over- or underdosing.

\section{Clinical Case: Bone Metastases}

During lactation, a 37-year-old woman was diagnosed with breast cancer, $8 \mathrm{~cm}$ in diameter, cT3 $\mathrm{N}+$. Treatment of the primary tumor consisted of neoadjuvant chemotherapy, mastectomy with axillary lymph node dissection, and adjuvant radiotherapy. Three months after the end of adjuvant radiotherapy, we saw this patient again with newly diagnosed bone metastases. She complained of pain in the lower back. Bone scan and computed tomography (CT) showed multiple lesions in the spine and pelvis, mainly osteolytic, especially in the lumbar spine and sacrum. We started therapy with bisphosphonates and irradiation of the lumbar spine, sacrum, and left ilium with 40 Gy in 20 fractions, which was well tolerated. Unfortunately, the patient developed pain in her right knee directly afterwards, and magnetic resonance imaging showed further metastasis in the right proximal fibula. This region was irradiated with $30 \mathrm{~Gy}$ resulting in rapid pain relief. Although the metastases in the thoracic spine where asymptomatic and not at risk of pathologic fracture, the patient was afraid of 
possible complications resulting from these bone lesions and insisted on treatment. After careful counseling, we decided to treat the thoracic spine with $30 \mathrm{~Gy}$. As her breast cancer was triple negative, the patient was offered chemotherapy with capecitabine afterwards. Now, 10 month after radiation of the bone metastases, the patient is in good condition, free of pain, and able to lead a normal life. Restaging shows that all scintigraphic bone lesions have disappeared, tumor markers are negative, and there are no sings of metastatic spread to lung and liver.

\section{Single Fraction versus Fractionated Radiotherapy}

More patients $(21.5 \%)$ need re-irradiation after single fraction radiotherapy because of recurring pain, compared to $7.4 \%$ after fractionated radiotherapy (meta-analysis [11]). In the case of recurrent pain, repeated radiotherapy showed the same relieving effect in $63 \%$ of patients as the first irradiation [13]. Fractionated radiotherapy is significantly more effective than single fraction radiotherapy with respect to restabilization and potentially avoiding fractures. An increase in bone density (restabilization) is visible after 4-6 months [14].

\section{Alleviation of Neurological Symptoms Caused by Metastatic Spinal Cord Compression}

Intraspinal metastases or an infiltration of the spinal cord by vertebral metastases can lead to spinal cord compression with motor and sensory deficits and pain. Radiotherapy should be started as soon as possible, i.e. within $24 \mathrm{~h}$ from the patient's first presentation $[15,16]$. Anti-edematous treatment with corticosteroids should be started immediately. Neurosurgical intervention prior to radiotherapy should be considered for selected patients [17]. A total of $10-15 \%$ of patients with spinal cord compression are likely to benefit from surgery and postoperative irradiation regarding their ability to walk and long-term local control. These are patients with a Karnofsky index higher than $70 \%$, a survival prognosis of at least 3 months, paraplegia no longer than $48 \mathrm{~h}$, and involvement of only one spinal segment. Patients who were able to walk at the beginning of radiotherapy have an $80 \%$ chance of retaining the ability to walk. In paraparesis, the probability of regaining the ability to walk decreases to $40 \%$, in paraplegia to $7 \%$. Fast progress of paralysis is less favorable than a more protracted development of motor deficits. In cases of slow development, neurologic deficits arise due to venous congestion which is mostly reversible. In cases of fast development, however, compression of the arterial vessels often occurs with subsequent spinal ischemia or even spinal cord infarction [15]. Improvement of pain and neurologic function (e.g. urinary dysfunction) after irradiation for spinal cord compression in the range of $25-80 \%$ has been reported in several studies ([18-20], overview [10]).

\section{Alleviation of Neurological Symptoms Caused by Brain Metastases and Leptomeningeal Carcinomatosis}

Breast cancer is the second most common cause of brain metastases (BM) amounting to $10-40 \%$ of patients who develop metastatic disease. Parenchymal metastases are found at autopsy in 30-40\%, and leptomeningeal central nervous system (CNS) metastases in 5-16\% of cases. The incidence of $\mathrm{BM}$ is increasing, particularly because improved systemic therapies lead to extended survival rates. BM can be the only site of progression in patients receiving systemic chemotherapy. Particularly patients with Her2/neu-positive tumors are at risk of developing $\mathrm{BM}+$ leptomeningeal carcinomatosis [21]. Historically, median survival after the diagnosis of BM is 4-6 weeks if untreated or if purely symptomatic medication like steroids is given. Retrospective analyses report a median survival for patients with BM from breast cancer of 4.2-6 months after whole brain radiotherapy (WBRT) alone, depending on the patient's general condition and the extent of extracranial disease [22-25].

\section{Brain Metastases}

For patients treated with radiotherapy, prognostic factors for survival are age, functional status, number of BM, systemic disease status, and the interval between primary diagnosis and development of BM [26, 27]. For breast cancer patients, hormone status and Her2/neu status also play an important role. The Recursive Partitioning Analysis (RPA) classification system is used to score patients with BM in order to assess their prognosis. It is based on the results of 3 RTOG (Radiation Therapy Oncology Group) studies with 1,200 patients with $\mathrm{BM}, 12 \%$ of them with breast cancer [28]. Patients with a Karnofsky index of $70 \%$ or more, aged $<65$ years, without extracerebral metastases, and with controlled primary tumor (RPA class 1 ) have the best prognosis with a median survival of 11.6 months. Patients in bad general condition with a Karnofsky index of $<70 \%$ (RPA class III) have a median survival time of only about 3 months. All other patients are classified RPA II with a median survival of 4-6 months. This classifications provides a framework for treatment decisions in individual cases: For patients with multiple BM, WBRT with 30-40 Gy is the mainstay of therapy. Short-term radiation $(5 \times 4$ Gy in 1 week) does not result in a worse prognosis when compared to $30 \mathrm{~Gy}$ in 10 fractions. Nevertheless, this shortened radiotherapy regimen with higher single doses should only be used in patients with an especially poor prognosis (RPA class III) to minimize the risk of radiogenic longterm consequences such as neurocognitive deficits. For patients with only 1-3 BM, an additional stereotactic boost may be beneficial [29]. RPA class I patients should be treated with either surgical resection or radiosurgery, followed by WBRT to prevent new intracranial metastases and death from BM [30]. In spite of a lack of randomized trials, survival is comparable for surgery and radiosurgery, and may reach a median 
survival of 11-17 months in this favorable group of patients [29-32]. In the case of a single BM but progressive extracranial disease or other unfavorable clinical features, WBRT alone is an adequate option [33].

The effect of radiotherapy on symptom control for BM is difficult to determine because medication with corticosteroids is usually started immediately and leads to a rapid improvement of neurological symptoms but can have negative effects, e.g. muscle weakness, drowsiness, sleep disturbances, and changes in physical appearance, especially if continued for a longer time. Overall, $75-80 \%$ of patients with multiple BM experience an improvement of preexisting neurological symptomatology after WBRT. Significant improvement of headaches was seen in $50-70 \%$ of patients, improvement of paresis in $30-40 \%$ of patients, and improvement of cerebral dysfunction in $40-50 \%$ of patients [34, 35].

Prospective studies on WBRT with the explicit endpoints 'alleviation of symptoms' or 'quality of life' are rare and the results are inconsistent. In one study, everyday life and health were significantly improved (29/54\%). Neurological function $(47 \%)$ and fatigue $(44 \%)$ were stable or improved, other areas of quality of life (e.g. weakness, memory loss, confusion) did not change significantly following WBRT (129 patients, [36]). Chow et al. [37], applying $10 \times 3$ Gy or $4 \times 5$ Gy to the neurocranium, showed a significant deterioration of fatigue, drowsiness, and appetite after WBRT using the Edmonton Symptom Assessment Scale (ESAS). Other symptoms did not change significantly (sense of well-being, pain, depression, anxiety, shortness of breath [37]. The study of the German DEGRO Quality of Life Working Party showed slightly improved scores for headaches and seizures after 3 months, but a significant deterioration of certain quality of life areas (drowsiness, hair loss, and weakness of legs (20/46 patients) ) [38]. Of 91 patients in bad general condition (Karnofski index 30-60\%), an improvement of clinical symptoms in a standardized quality of life assessment was reported in $35 \%$ of cases, and in $61 \%$ of cases an increase in symptoms (for example fatigue, hair loss) was reported. In the open questions at the end of the survey, a significantly higher number of patients evaluated WBRT more positively (75\% stated symptom improvement), and only $7 \%$ of patients would not undergo radiotherapy again. Coping strategies can influence the re-assessment. Independent from WBRT, changing results of quality of life surveys might also be caused by disease progression at other locations. Further examinations are necessary to define patient-oriented outcome criteria and to avoid overtreatment.

\section{Leptomeningeal Carcinomatosis}

Breast cancer is the most common underlying disease for leptomeningeal carcinomatosis from solid tumors [39]. Diffuse leptomeningeal carcinomatosis has a bad prognosis with a median survival of only a few weeks if untreated. Intensive treatment like radiotherapy of the neurocranium or intrathe- cal chemotherapy will extend this to a few months. The formerly used irradiation of the whole cranio-spinal axis was abandoned because of myelotoxicity, especially in adult patients pretreated with multiple regimens of chemotherapy. For large intraspinal masses that cause pain and/or neurological symptoms and hinder circulation of cerebrospinal fluid (thus impairing intrathecal cytostatic treatment), local radiotherapy is indicated and often results in rapid improvement of symptoms $[40,41]$.

\section{Pain, Bleeding, and Ulceration Caused by Locally Advanced Breast Cancer, Lymph Node Metastases, or Soft Tissue Metastases}

Patients with locally advanced breast cancer with lymph node or soft tissue metastases are treated with a combination of surgery, radiation therapy, and chemotherapy with the aim of local control and prolonging survival time. Patients with an isolated inoperable tumor mass should receive radiotherapy [41]. Long-term radiotherapy prevents adverse consequences of uncontrolled growth of locoregional disease (5-year local control rates $25-77 \%$ ) [42-44]. In situations with a short survival prognosis, symptoms like pain, bleeding, or exulceration, and smelling can be stopped by short-term radiotherapy with higher doses per fraction. Radiotherapy leads to a quick reduction in the size of ulcerated tumors and thus to pain relief; in the weeks following radiotherapy, healing of the defects can often be observed (see Clinical Case). For superficial tumors, radiotherapy with fast electrons is recommended. Deep-seated tumors are radiated with photons after CT-based 3-D planning. An initial increase in the size of the ulcerated tumor due to inflammation caused by tumor necrosis is common. With local irradiation of ulcerating tumors, wound treatment is simplified, and superinfection, unpleasant smells and distortion are reduced (fig. 2).

\section{Patient Information, Requirements, Assessment, and Decision Making}

Decisions regarding treatment in a palliative situation have to always be made individually for each patient. When determining radiotherapy for symptom control, the patient's prognosis, quality of life, performance status, level of distress, and individual resources regarding the practical requirements of radiotherapy (e.g. daily trips to therapy, positioning on the treatment couch during irradiation) need to be integrated in an individual concept. The intention and goals of therapy must be communicated to the patients and - if desired - also to the relatives. A survey of patients with advanced cancer showed that a significant proportion of patients had misconceptions regarding their illness and unrealistic expectations of palliative radiotherapy [45]. On the other hand, the 
radiotherapist's communication style can be affected by the treatment intention [46]. Shared decision making is widely accepted as an option to improve patients' participation in an evidence-based collaborative approach [47, 48]. Patient surveys have shown that this is also possible and required in palliative radiotherapy $[49,50]$. The importance of shared decision making has now also been recognized by the health care sector and the initiative Nationaler Krebsplan (National Cancer Plan). Special training programs are being developed to enable patients and medical staff to follow the principles of shared decision making.

\section{Conclusions}

Radiotherapy for symptom control is an important treatment option for breast cancer patients. Pain, neurological symptoms, symptoms of obstruction and compression, bleeding, or exulceration in advanced breast cancer can be effectively con- trolled. Dose fractionation and the type of radiotherapy must be tailored to each patient individually, taking into account the patient's perspective, goals of treatment, and prognosis. In the case of limited life expectancy, irradiation should be performed with higher doses per fraction and a short overall treatment time. Selection of the individual palliative treatment concept including radiotherapy should be performed in a multidisciplinary and multiprofessional team. Patients and perhaps relatives should participate in the decision making process. A closer cooperation between patients, relatives, radiation oncologists, other physicians, and other members of the palliative team is required to achieve the maximum benefit from radiotherapy for patients in a palliative situation.

\section{Disclosure Statement}

The authors confirm that there are no primary financial relationships with any companies.

\section{References}

1 AWMF-Leitlinie «Diagnostik, Therapie und Nachsorge des Mammakarzinoms der Frau» Stand 4/2008,www.uni-duesseldorf.de/awmf/ll/ll_077.htm.

- 2 Thomssen C, Harbeck N; on behalf of the AGO Update 2010 of the German AGO recommendations for the diagnosis and treatment of early and metastatic breast cancer: chapter B: prevention, early detection, lifestyle, premalignant lesions, DCIS, recurrent and metastatic breast cancer. Breast Care 2010;5:345-351.

$>3$ Souchon R, Wenz F, Sedlmayer F, Budach W, Dunst J, Feyer P, Haase W, Harms W, Sautter-Bihl M, Sauer R: DEGRO Practical Guidelines for palliative radiotherapy of metastatic breast cancer: bone metastases and metastatic spinal cord compression. Strahlenther Onkol 2009;7:417-424.

4 Feyer P, Sautter-Bihl ML, Budach W, Dunst J, Haase W, Harms W, Sedlmayer F, Souchon R, Wenz F, Sauer R; Breast Cancer Expert Panel of the German Society of Radiation Oncology (DEGRO): DEGRO Practical Guidelines for palliative radiotherapy of breast cancer patients: brain metastases and leptomeningeal carcinomatosis. Strahlenther Onkol 2010;186:63-69.

$\checkmark 5$ Coleman RE: Clinical features of metastatic bone disease and risk of skeletal morbidity. Clin Cancer Res 2006;12:6243-6249.

6 Clemons M, Dranitsaris G, Cole D, Gainford MC: Too much, too little, too late to start again? Assessing the efficacy of bisphosphonates in patients with bone metastases from breast cancer. Oncologist 2006;11:227-233.

7 Janjan N, Lutz ST, Bedwinek LM, Hartsell WF, $\mathrm{Ng} \mathrm{A}$, Pieters RS Jr, Ratanatharathorn V, Silberstein EB, Taub RJ, Yasko AW, Rettenmaier A: Therapeutic guidelines for the treatment of bone metastasis: a report from the American College of Radiology Appropriateness Criteria Expert Panel on Radiation Oncology. J Palliat Med 2009;12:417426.

$>8$ Rades D: Dose-fractionation schedules for radiotherapy of bone metastases. Breast Care 2010;5: 339-344.
9 Niewald M, Tkocz HJ, Abel U, Scheib T, Walter K, Nieder C, Schnabel K, Berberich W, Kubale R, Fuchs M: Rapid course radiation therapy vs. more standard treatment: a randomized trial for bone metastases. Int J Radiat Oncol Biol Phys 1996;36:1085-1089.

10 Roos DE, Turner SL, O'Brian PC, Smith JG, Spry NA, Burmeister BH, Hoskin PJ, Ball DL, Trans-Trasman Radiation Oncology Group, TROG 96.05: Randomized trial of 8Gy in 1 versus $20 \mathrm{~Gy}$ in 5 fractions of radiotherapy for neuropathic pain due to bone metastases. Radiother Oncol 2005;71:54-63.

11 Wu JS, Wong R, Johnston M, Bezjak A, Whelan T: Meta-analysis of dose-fractionation radiotherapy trials for the palliation of painful bone metastases. Int J Radiat Oncol Biol Phys 2003;55:594-605.

12 Sze WM, Shelley M, Held I, Mason M: Palliation of metastatic bone pain: single fraction versus multifraction radiotherapy - a systematic review of the randomized trials. Cochrane Database Syst Rev 2004(2):CD004721.

13 Van der Linden YM, Lok JJ, Steenland E, Martijn $\mathrm{H}$, van Houwelingen H, Marijnen CA, Leer JW: Single fraction radiotherapy is efficacious: a further analysis of the Dutch Bone Metastasis Study controlling for the influence of retreatment. Int J Radiat Oncol Biol Phys 2004;59:528-537.

14 Koswig S, Budach V: Remineralisation und Schmerzlinderung von Knochenmetastasen nach unterschiedlich fraktionierter Strahlentherapie $(10 \times 3$ Gy vs. $1 \times 8$ Gy). Strahlenther Onkol 1999;175:500-508.

15 Rades D, Heidenreich F, Karstens JH: Final results of a prospective study of the prognostic value of the time to develop motor deficits before irradiation in metastatic spinal cord compression. Int J Radiat Oncol Biol Phys 2002;53:975-979.

16 Tang V, Harvey D, Park Dorsay J, Jiang S, Rathbone MP: Prognostic indicators in metastatic spinal cord compression: using functional independence measure and Tokuhashi scale to optimize rehabilitation planning. Spinal Cord 2007;45:671-677.
17 Patchell RA, Tibbs PA, Regine WF, Tibbs PA, Wilson D, Shappley D, Young BY: Direct decompressive surgical resection in the treatment of spinal cord compression caused by metastatic cancer: a randomised trial Lancet 2005;366:643-648.

18 Rades D, Stalpers LJ, Hulshof MC, Zschenker O, Alberti W, Koning CC: Comparison of $1 \times 8$ Gy and $10 \times 3$ Gy for functional outcome in patients with metastatic spinal cord compression. Int J Radiat Oncol Biol Phys 2005;62:514-518.

19 Maranzano E, Latini P, Checcaglini F, Perrucci E, Aristei C, Panizza BM, Ricci S: Radiation therapy of spinal cord compression caused by breast cancer: report of a prospective trial. Int J Radiat Oncol Biol Phys 1992;24:301-306.

20 Rades D, Abrahm JL: The role of radiotherapy for metastatic epidural spinal cord compression. Nat Rev Clin Oncol 2010;7:590-598.

21 Lai R, Dang CT, Malkin MG, Abrey LE: The risk of central nervous metastases after trastuzumab therapy in patients with breast carcinoma. Cancer 2004;10:810-816.

22 Mahmoud-Ahmed AS, Suh JH, Lee SY, Crownover RL, Barnett GH: Results of whole brain radiotherapy in patients with brain metastases from breast cancer: a retrospective study. Int J Radiat Oncol Biol Phys 2002;54:810-817.

23 Lentzsch S, Reichardt P, Weber F, Budach V, Dörken B: Brain metastases in breast cancer: prognostic factors and management. Eur J Cancer 1999;35:580-585.

24 Mizutani Y, Yamashita T, Sakamoto G: Radiation therapy for brain metastases from breast cancer by histological classification. Nippon Igaku Hoshasen Gakkai Zasshi 2001;61:89-95.

25 Fokstuen T, Wilking N, Rutqvist LE, Wolke J; Liedberg A: Radiation therapy in the management of brain metastases from breast cancer. Breast Cancer Res and Treat 2000;62:211-216.

26 Rades D, Dunst J, Schild SE: A new scoring system to predict the survival of patients treated with whole-brain radiotherapy for brain metastases. Strahlenther Onkol 2008;184:251-255. 
27 Sperduto PW, Berkey B, Gaspar LE, Mehta M, Curran W: A new prognostic index and comparison to three other indices for patients with brain metastases: an analysis of 1,960 patients in the RTOG database. Int J Radiat Oncol Biol Phys 2008;70:510-514.

-28 Gaspar L, Scott C, Rotman M, Asbell S, Phillips T, Wasserman T, McKenna WG, Byhardt R: Recursive partitioning analysis (RPA) of prognostic factors in three Radiation Therapy Oncology Group (RTOG) brain metastases trials. Int J Radiat Oncol Biol Phys1997;37:745-751.

-29 Andrews DW, Scott CB, Sperduto PW, Flanders AE, Gaspar LE, Schell MC, Werner-Wasik M, Demas W, Ryu J; Bahary JP, Souhami L, Rotman M, Mehta MP, Curran WJ Jr: Whole brain radiation therapy with or without stereotactic radiosurgery boost for patients with one to three brain metastases: phase III results of the RTOG 9508 randomized trial. Lancet 2004;363:1665-1672.

-30 Kirsch D, Loeffler JS: Brain metastases in patients with breast cancer: new horizons. Clin Breast Cancer 2005;6:115-124.

-31 Kondziolka D, Patel A, Lunsford LD, Kassam A, Flickinger JC: Stereotactic radiosurgery plus whole brain radiotherapy alone for patients with multiple brain metastases. Int J Radiat Oncol Biol Phys 1999;45:427-434.

-32 Sanghavi SN, Miranpuri SS, Chappell R, Buatti JM, Sneed PK, Suh JH, Regine WF, Weltman E, King VJ, Goetsch SJ, Breneman JC, Sperduto PW, Scott C, Mabanta S, Mehta MP: Radiosurgery for patients with brain metastases: a multi-institutional analysis, stratified by the RTOG recursive partitioning analysis method. Int $\mathrm{J}$ Radiat Oncol Biol Phys 2001;51:426-434.
33 Noordijk EM, Vecht CJ, Haaxma-Reiche H, Padberg GW, Voormolen JH, Hoekstra FH, Tans JT, Lambooij N, Metsaars JA, Wattendorff AR: The choice of treatment of a single brain metastasis should be based on extracranial tumor activity and age. Int J Radia Oncol Biol Phys 1994;29:711-717.

34 Lagerwaard FJ, Levendag PC, Nowak PJ, Eijkenboom WM, Hanssens PE, Schmitz PI: Identification of prognostic factors in patients with brain metastases: a review of 1292 patients. Int J Radiat Oncol Biol Phys 1999;43:795-803.

35 Glanzmann C: Palliative Radiotherapie von Hirnmetastasen solider Tumoren: Erfahrungen mit hohen Dosen. Strahlenther Onkol 1990;166:119124

36 Wong J, Hird A, Kirou-Mauro A, Napolskikh J, Chow E: Quality of life in brain metastases radiation trials: a literature review. Curr Oncol 2008;15:25-45.

37 Chow E, Davis L, Holden L, Fung KW, Schueller T, Wong R, Hayter C, Szumacher E, Loblaw A, Danjoux C: Prospective assessment of patient-rated symptoms following whole brain radiotherapy for brain metastases. J Pain Symptom Manage 2005;30:18-23.

38 Steinmann D, Schäfer C, van Oorschot B, Wypior HJ, Bruns F, Bölling T, Sehlen S, Hagg J, Bayerl A, Geinitz H, Hipp M, Vordermark D: Effects of radiotherapy for brain metastases on quality of life (QoL). Prospective pilot study of the DEGRO QoL working party. Strahlenther Onkol 2009;185:190-197.

39 Wasserstrom WR, Glass JP, Possner JB: Diagnosis and treatment of leptomeningeal metastases from solid tumors: experience with 90 patients. Cancer 1982:49:759-772.

40 De Angelis LM: Current diagnosis and treatment of leptomeningeal metastasis. J Neurooncol 1998;38:245-252.
41 Schwaibold F, Fowble BL, Solin LJ, Schultz DJ, Goodman RL: The results or radiation therapy for isolated regional recurrence after mastectomy. Int J Radiat Oncol Biol Phys 1991;21:299-310.

42 Buchholz T: Breast cancer: locally advanced and recurrent disease, postmastectomy radiation and systemic therapy; in Halperin EC, Perez CA, Brady LW (eds): Principles and Practice of Radiation Oncology. Philadelphia, PA, Lippincott Williams\&Wilkins, 2007, pp. 1292-1316.

43 Newman LA, Hunt KK, Buchholz T, Kuerrer HM, Vlastos G, Mirza N, Ames FC, Ross MI, Singletary SE: Presentation, management and outcome of axillary recurrence from breast cancer. Am J Surg 2000;180:252-256.

44 Aberizk WJ, Silver B, Henderson IC, Cady B, Harris JR: The use or radiotherapy for treatment of isolated loco-regional recurrence of breast carcinoma after mastectomy. Cancer 1986;58:12141218.

45 Herfarth KK, Debus J, Lohr F, Bahner ML, Wannenmacher M: Stereotactic irradiation of liver metastases. Radiologe 2001;41:64-68.

46 Greco C, Catalano G, Di Grazia A, Orecchia R Radiotherapy of liver malignancies. From whole liver irradiation to stereotactic hypofractionated radiotherapy. Tumori 2004;90:73-79.

47 Wulf J, Guckenberger M, Haedinger U, Oppitz U, Mueller G, Baier K, Flentje M: Stereotactic radiotherapy of primary liver cancer and hepatic metastases. Acta Oncol 2006;45:838-847.

48 Swaminath A, Dawson LA: Emerging role of radiotherapy in the management of liver metastases. Cancer J 2010;16:150-155.

49 Combs SE, Herfarth KK, Habermehl D, Debus J: (Radiotherapy of hepatic metastases). Chirurg 2010;81:526-532.

50 Borgelt BB, Gelber R, Brady LW, Griffin T, Hendrickson FR: The palliation of hepatic metastases: results of the Radiation Therapy Oncology Group pilot study. Int J Radiat Oncol Biol Phys 1981;7:587-559. 